\title{
Comparison of coupling capacitors and the inverter filter in partial discharge phenomena on rotating machines supplied by IFDs
}

\author{
S. M. Hassan Hosseini ${ }^{1}$, A. Doroozi ${ }^{2}$ S. Soleimani ${ }^{3}$ \\ 1, 2, 3 (Department of Electrical Engineering, Islamic Azad University South Tehran Branch, Tehran, IRAN)
}

\begin{abstract}
: offline and online measurement of partial discharge phenomena is necessary to prevent induction machine from premature insulation failure. An inverter output includes pulses of voltage rapidly and it is known that this type of voltages lead to aged insulation and premature insulation failure. The reason is excessive voltage proportional to the rise time of the inverter and cable length. When the rise time is greater, the excessive voltage will be less. This can be done by putting a filter on the inverter output. In this paper, an online partial discharge signals measurement in rotating induction machine fed by inverters without placing the filter on the inverter output and use coupling capacitors with different capacities to assess and compare their impact on machine performance and partial discharge detection, is done. Finally the machine performance has been studied and is compared with the use of appropriate capacity of coupling capacitors and inverter filter at output of the inverter. The model of the rotating machine and power cable is in high frequency because is fed by an inverter in order to visualize the overvoltage and partial discharge phenomena and it was developed using simulation in Matlab Simulink ${ }^{T M}$.
\end{abstract}

Keywords : Partial discharges, Filter, Induction machine, Coupling Capacitors, inverter

\section{INTRODUCTION}

When the inverter fed induction motor, an over voltage is developed. One reason for this over voltage is the inverter switching devices in power electronics. Pulses that are sent to an inverter raised two issues: the rise time of the inverter and the high frequencies. So, motors and cables connected to it are under the influence of high-frequency, so high-frequency models of behavior must be considered. If the rise time is shorter, the peak voltage insulation resistance will be less, so the inverters manufacturers are consider constraints for the rise time. According to wave reflection, voltage impulse travels through the cable at the velocity of 150-200 meters per microsecond and after it arrives to the machine and sees a mismatch of surge impedance between the cable and machine, voltage impulse reflects with proportion of cable and machine impedance and return to the inverter. At this time the machine over voltage are developed. Arrived wave to the inverter is reflected in the negative range, and this is repeated continuously [1], [3]. This proves to us that the cable length and rise time are two important factors for determining the over voltages at the motor terminals [2].

This is lead to electrical stress in the interturn insulation and core insulation and causes aging of the general machine insulation, increasing of the dielectric loss and causing partial discharge. If partial discharge occurs rapidly, it will lead to total destruction of the insulation and miss the machine and increase repair cost. Online partial discharge measurement has advantages upon offline measurement such as:

- Test the machines without taking them out of service.

- Decrease the time of the taking out the machine.

- Personnel are more prepared to deal with the inconvenience.

- Not require high voltage equipment.

- More safety.

Simulations presented in this paper are accurate. For example, the machine model is designed to high frequencies for analysis [6]. We can use series inductance filters in inverter output to increase rise time, in this case over voltages at the motor terminal is reduced, and the possibility of reaching to partial discharge inception voltage is minimizes [5]-[9].

In this paper, to measure the partial discharge signal we use the coupling capacitor sensor in series with a resistor connected to ground which after filtering and separating signal from noise is shown in scope. 80 Pico farad coupling capacitors were used several years for partial discharge detection in high voltage rotary machines. But in low voltage machines, because partial discharge signal power is weak, we need sensitive sensor because however strong partial discharge signals with low frequency can cause poor insulation problem, weak partial discharge signals with high frequency can also be harmful to insulation. So we shouldn't ignore the weak partial discharge signal. So we use the coupling capacitor have different capacities to see their influence and compare the detection sensitivity and performance. 


\section{SIMULATED COMPONENTS}

To obtain accurate results from simulation, cables should be studied at high frequencies. To do this, frequency response of the cable and tested experimentally obtained and a model that is consistent with our results, is suggested. In this way, the frequency response of the cable obtained in two short circuit and open circuit mode, and uses them to create model of the cable. Set of series parameters describing the cable in short-circuit mode and the parallel parameters describing the cable in open circuit mode [7]. This model is shown in figure 1.

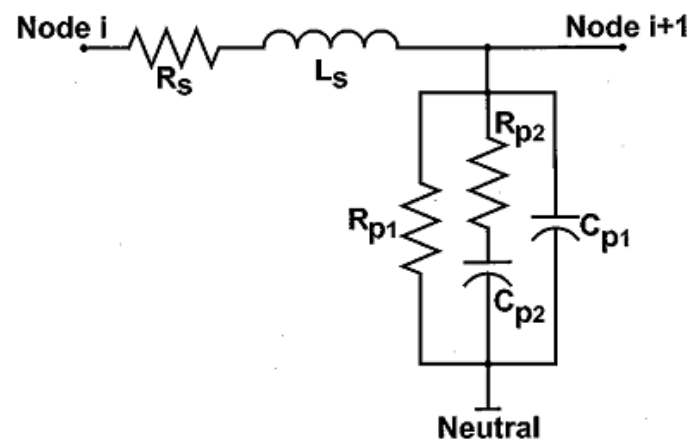

Figure 1. High frequency cable model

Performance of induction machine with considering magnetic core effects, winding to frame capacitors, and skin effects of windings, at high frequencies, should be assessed and an appropriate model for analyzing over voltages of the machine is presented.

In the paper [6] the author, an analytical equation and the resonance point in measured impedance versus frequency in both the common and differential has been introduced. Note that the frequency response of the model of induction motor $100 \mathrm{HP} 460 \mathrm{~V}$-Delta, $60 \mathrm{~Hz}$ at low and high frequencies (about 10 megahertz), is very close to the measured in both common and differential mode. Therefore, this model is well suited for the analysis of over voltages. The model is shown in Figure 2.

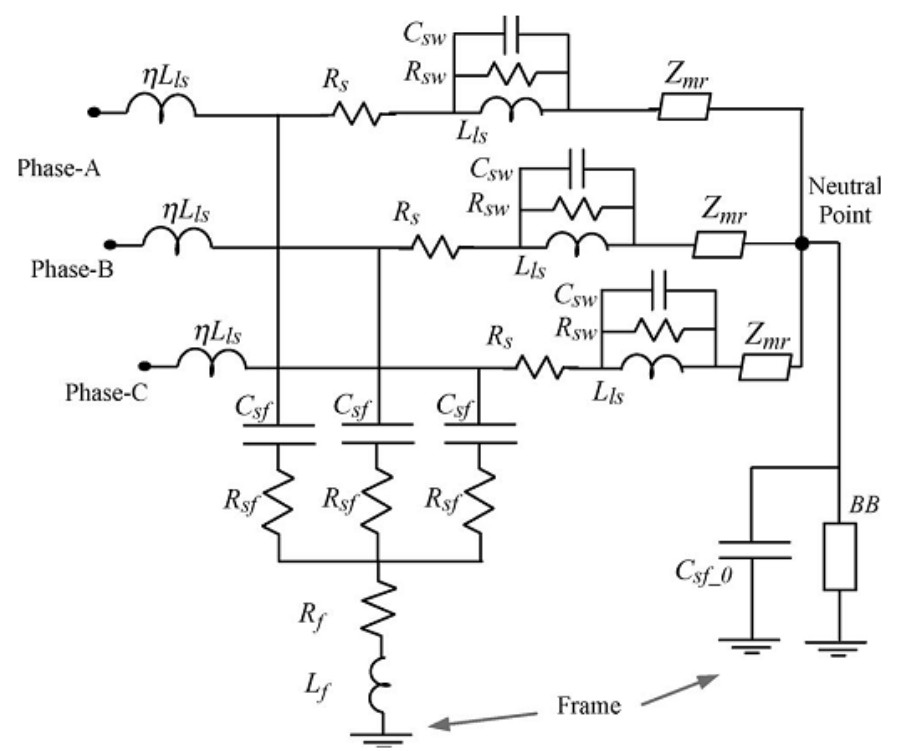

Figure 2. High frequency induction machine model

$$
\text { Figure } 3 .
$$

\section{ONLINE PARTIAL DISCHARGE MEASURMENT}

The use of high voltage capacitors (coupling capacitors) on the equipment terminal for measuring partial discharge is very common. Another widespread way is used $100 \mathrm{kHz}$ to $30 \mathrm{MHz}$ frequency bandwidth of current transformer associated with resistance $50 \Omega$. Also there are other options such as electromagnetic couplers and antenna type couplers. These sensors are sensitive to the high frequency signals from partial discharge. Using filtering techniques we can get useful information from the sensor signal and the noise in the system can be isolated. At offline or online detection, coupling capacitors blocks signals of power frequency $(60 \mathrm{~Hz})$ and will pass high-frequency signals from partial discharge (due to low resistance at high frequencies) [8].

Minimum voltage at which partial discharge occurs to call PDIV [4]. When the voltage reaches this limit, the partial discharge occurs according to the voltage of the switching function from the inverter and repetition rate level. 
In this paper, the coupling capacitor is used for detection and the simulated machine 100HP 460V-Delta, $60 \mathrm{~Hz}$ model [6] and simulated cable model [7] is used.

Coupling capacitors of $80 \mathrm{pF}, 500 \mathrm{pF}, 5 \mathrm{nF}, 50 \mathrm{nF}, 500 \mathrm{nF}, 50 \mu \mathrm{F}, 5 \mu \mathrm{F}$ used to compare and evaluate sensitivity in detection of partial discharge signals and machine performance in different conditions. The coupling capacitors can withstand the $10 \Omega$ to $500 \Omega$ series detector resistance [4] where at here we used $40 \Omega$ detector resistance.

\section{SimUlation RESULT}

Simulated block diagram shown in Figure 3. 3AWG cable length of $30 \mathrm{~m}$ with model parameters of the unit length Rs $=0.5 \mathrm{~m} \Omega, \mathrm{Ls}=0.22 \mu \mathrm{H}, \mathrm{Rp} 1=148.1 \mathrm{M} \Omega, \mathrm{Rp} 2=6.1 \mathrm{k} \Omega, \mathrm{Cp} 1=151.2 \mathrm{pF}, \mathrm{Cp} 2=26.3 \mathrm{pF}$ is used. The machine 100HP 460V-Delta, $60 \mathrm{~Hz}$ parameters are given in reference [6]. An inverter with 100 nanosecond rise time and bus voltage DC 650 and six PWM pulse $60 \mathrm{~Hz}$ is used. Also the high-pass filter cutoff frequency $2 \mathrm{MHz}$ is used [10].

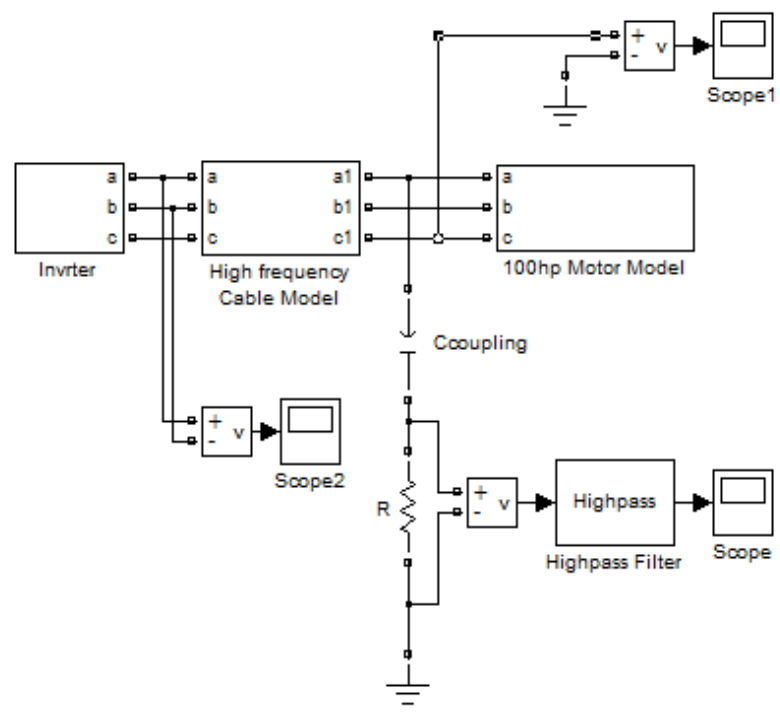

Figure 4. Simulated block diagram

Square pulses with very short rise time of the inverter is one reason of the over voltage at machine [2]. The shorter rise time, lead to highest over voltage and probability to reach inception voltage will be more. Figure 4 shows the inverter output voltage between phases a and $b$. The pulse rise time is 100 nanoseconds. Figures 5, 6, 7 show terminal voltage-phase machine and inverter output. It is clear that at rising and falling edge of the output voltage pulse inverter, over voltage occurs in machine terminals. These figures are for implement $80 \mathrm{nF}$ coupling capacitor. It is significant that at this moment the motor voltage reached to 900 volts that is 250 volts more than DC bus voltage. Small distortion is observed in every phase due the induction voltage from the other winding which were over voltage developed.

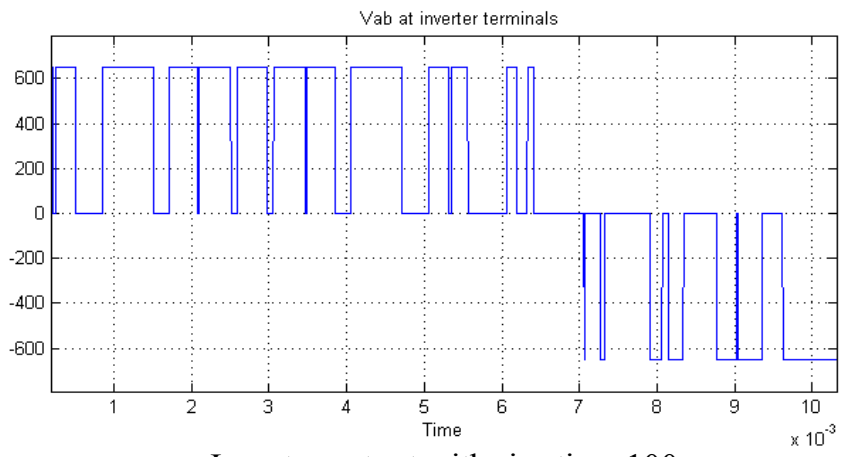

Figure 5. Inverter output with rise time $100 \mathrm{~ns}$ 


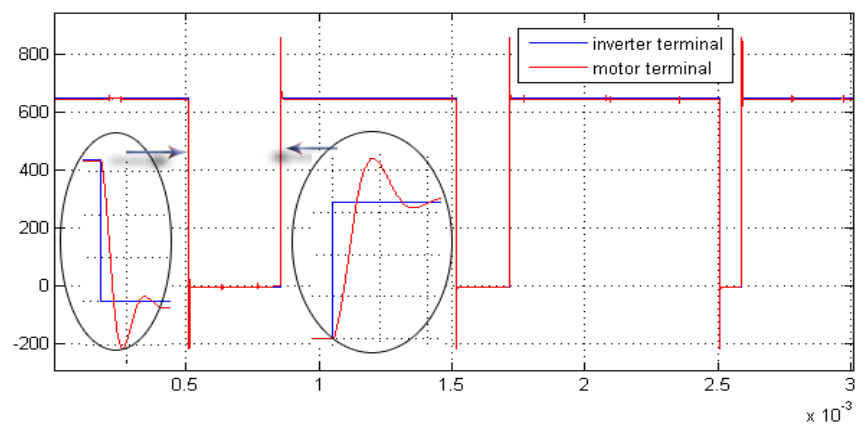

Figure 6. Over voltage at machine terminal at phase a

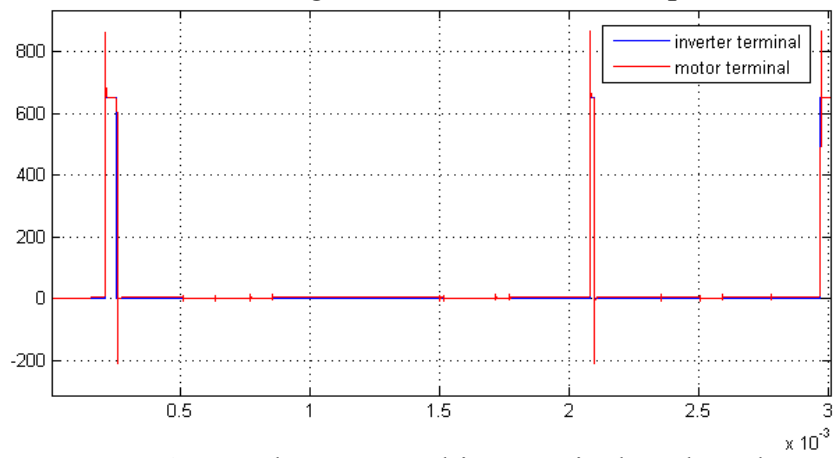

Figure 7. Over voltage at machine terminal at phase $b$

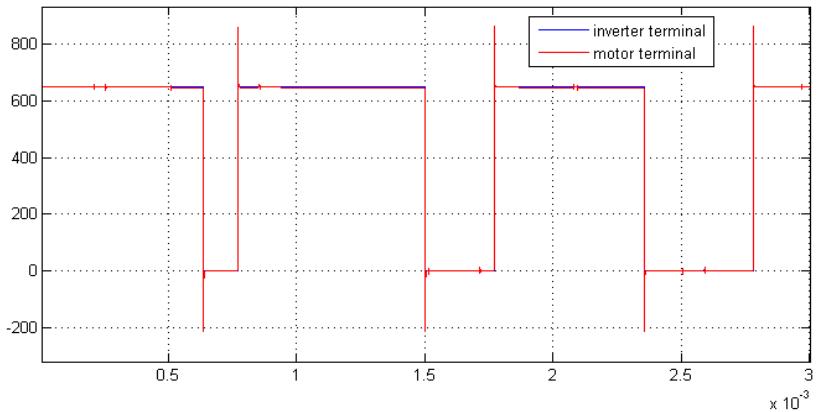

Figure 8. Over voltage at machine terminal at phase $\mathrm{c}$

As you can see in Figures 5 to 7, in each phase, between the over voltages due from inverter pulses, at the machine terminals we can see small distortions resulting from the induced voltage from winding of the other phases.

Figures 8 to 21 show the machine terminal voltage and partial discharge signals after passing through the filter that measured with the different quantities coupling capacitors.

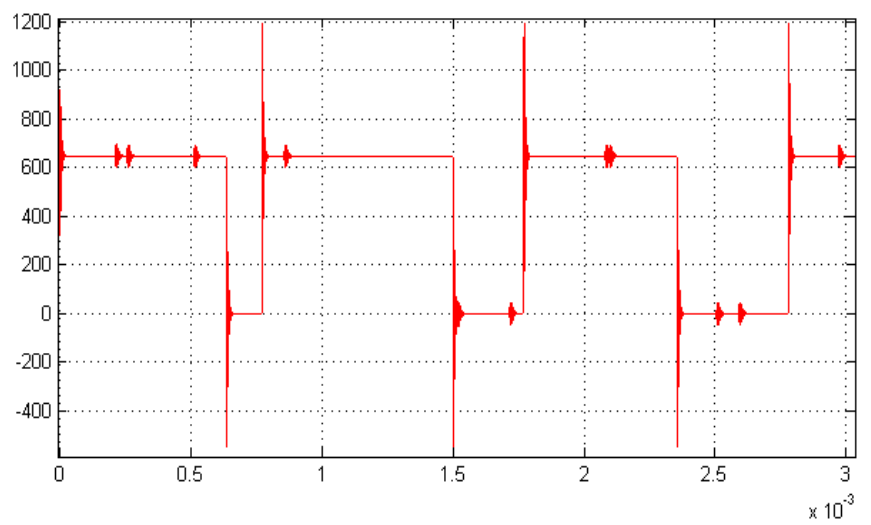

Figure 9. Machine terminal voltage with $80 \mathrm{pF}$ coupling capacitor 


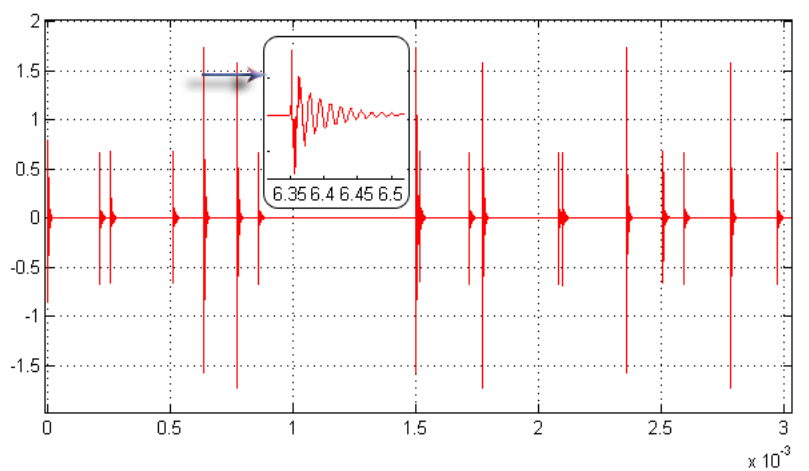

Figure 10. Detected partial discharge with $80 \mathrm{pF}$ coupling capacitor

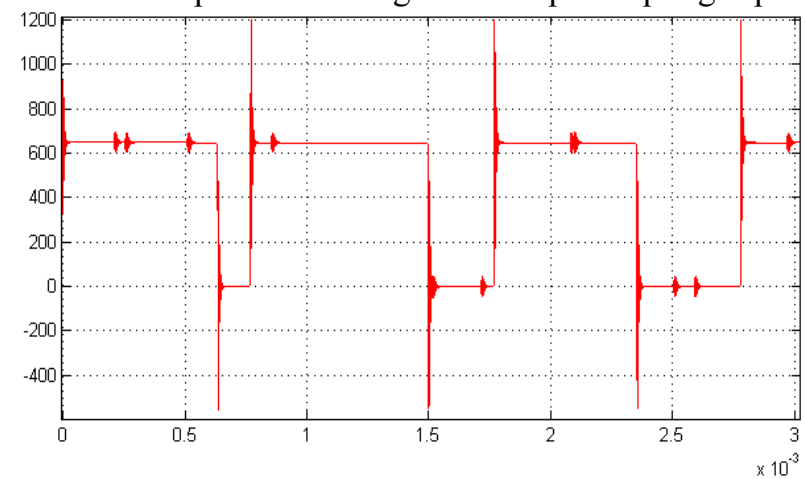

Figure 11. Machine terminal voltage with $500 \mathrm{pF}$ coupling capacitor

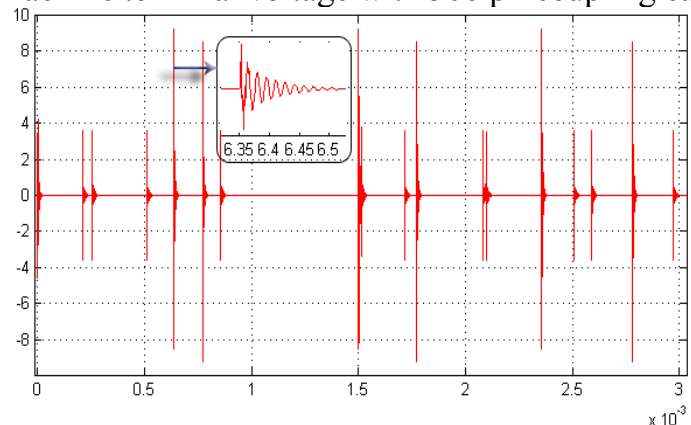

Figure 12. Detected partial discharge with $500 \mathrm{pF}$ coupling capacitor

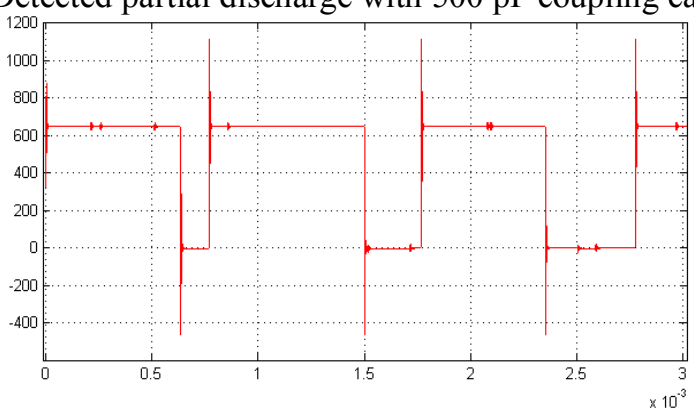

Figure 13. Machine terminal voltage with $5 \mathrm{nF}$ coupling capacitor

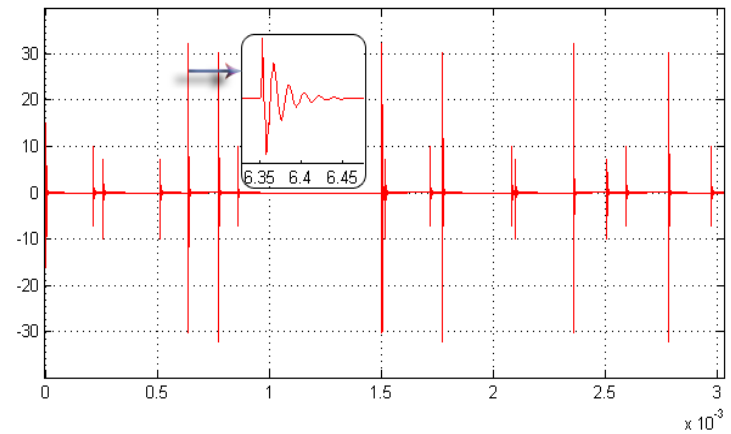

Figure 14. Detected partial discharge with $5 \mathrm{nF}$ coupling capacitor 


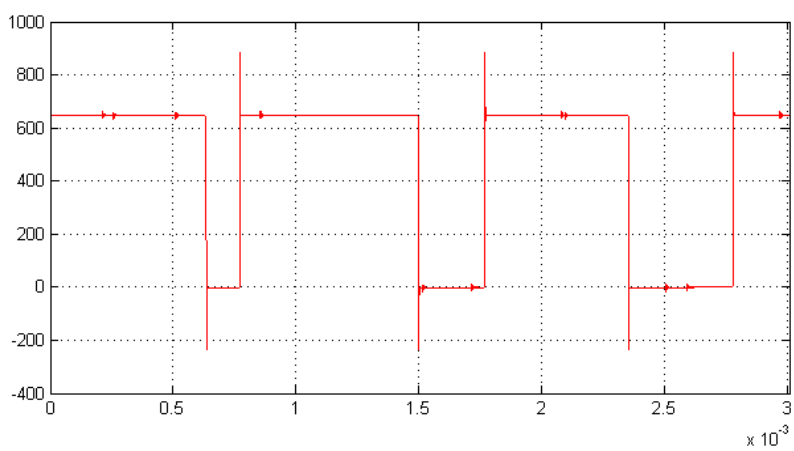

Figure 15. Machine terminal voltage with $50 \mathrm{nF}$ coupling capacitor

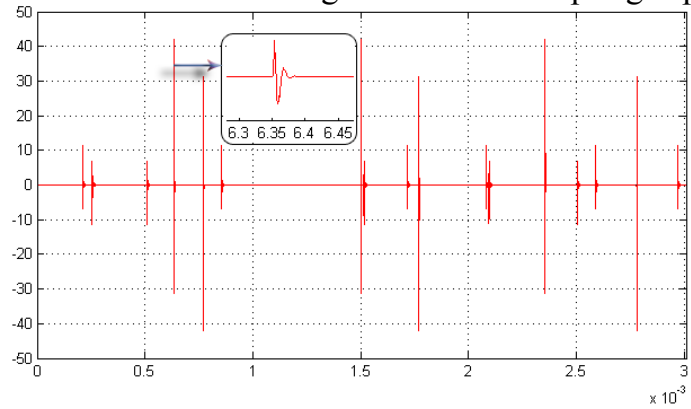

Figure 16. Detected partial discharge with $50 \mathrm{nF}$ coupling capacitor

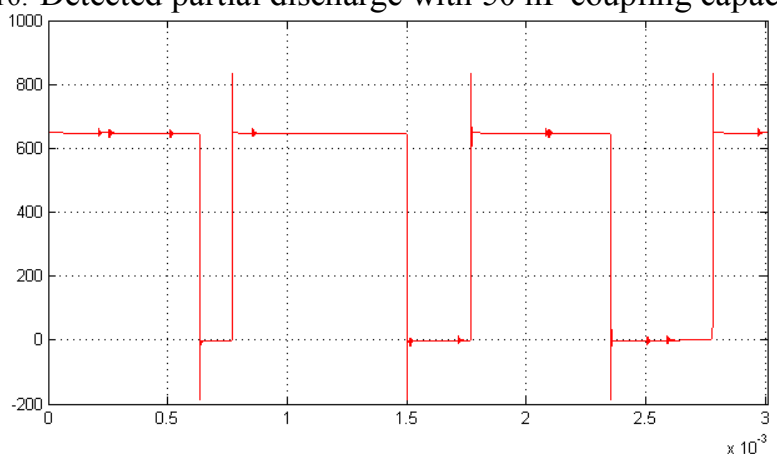

Figure 17. Machine terminal voltage with $500 \mathrm{nF}$ coupling capacitor

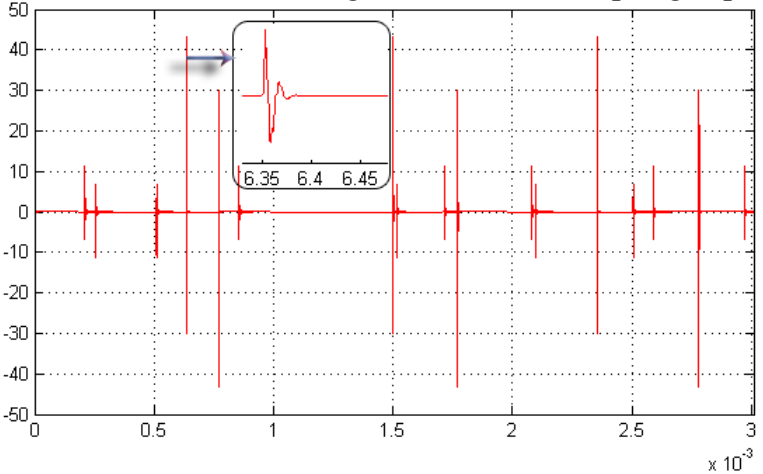

Figure 18. Detected partial discharge with $500 \mathrm{nF}$ coupling capacitor

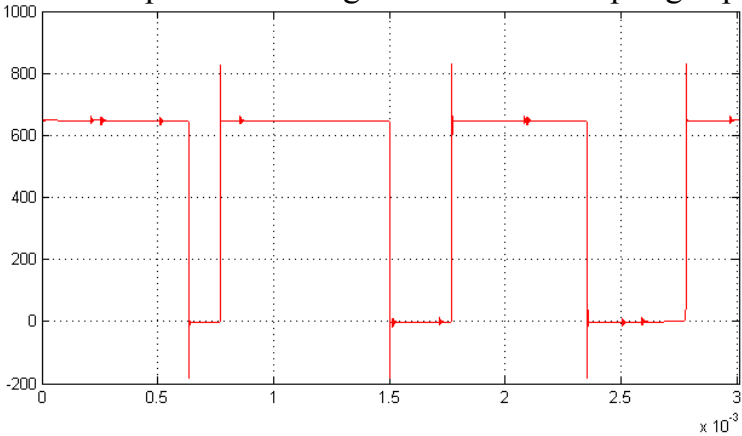

Figure 19. Machine terminal voltage with $5 \mu \mathrm{F}$ coupling capacitor 


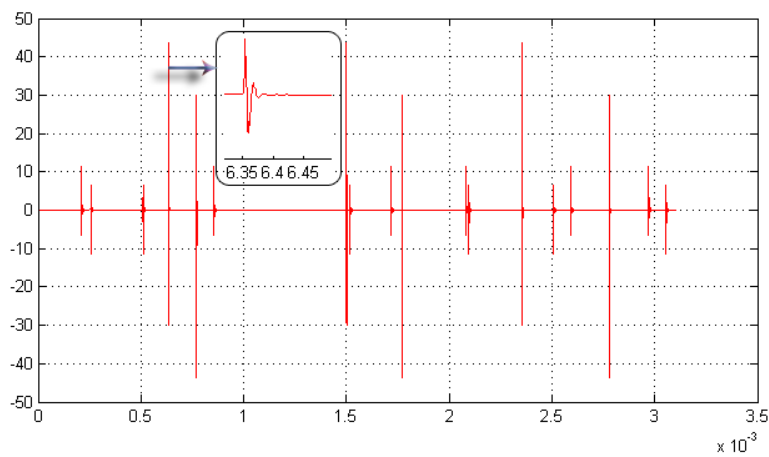

Figure 20. Detected partial discharge with $5 \mu \mathrm{F}$ coupling capacitor

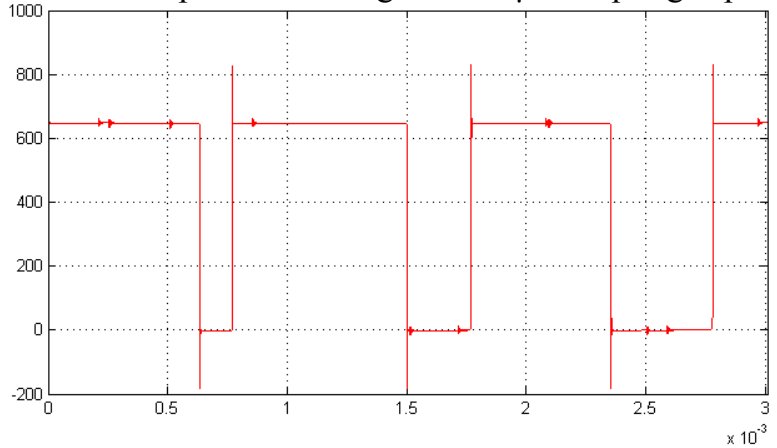

Figure 21. Machine terminal voltage with $50 \mu \mathrm{F}$ coupling capacitor

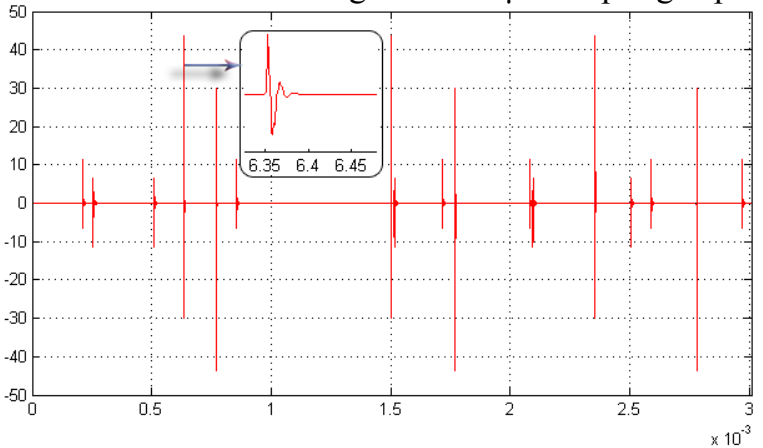

Figure 22. Detected partial discharge with $50 \mu \mathrm{F}$ coupling capacitor

As evident from the figures, increasing coupling capacitor capacity to $500 \mathrm{nF}$, lead to decrease the over voltage of the machine terminals and attenuation time of partial discharge signal is reduced and the amplitude of the partial discharge signal increases and it increase the signal to noise ratio and system sensitivity will be higher. For quantities greater than the $500 \mathrm{nF}$, reduction of over voltage and attenuation time, and increscent the amplitude of the signal will be negligible. Also with this amount of capacity of coupling capacitors, voltage signals that obtained is similar to daubechies mother wavelet has many, so the wavelet transform method can be is used to detect the signal. First, by $80 \mathrm{pF}$ coupling capacitor, the over voltage of machine terminal reach to 1200 $\mathrm{V}$ that is $550 \mathrm{~V}$ more than DC bus bar voltage. This moment, is the best time to start partial discharge. At while by coupling capacitor $500 \mathrm{nF}$ the over voltage reach to $830 \mathrm{~V}$ that is only $180 \mathrm{~V}$ more than DC bus bar voltage. Also by coupling capacitors $500 \mathrm{nF}$ (or greater) we can detect rising and falling edges of signals from the inverter. Falling edges signals have more positive range and the rising edge signals have more negative range. It could be used for inverter preventive maintenance and predict errors before they occur.

However, in order to increase the rise time of the inverter to $2 \mu \mathrm{s}$, at the inverter output we use low-pass filters that shown in figure 22 [9]. 


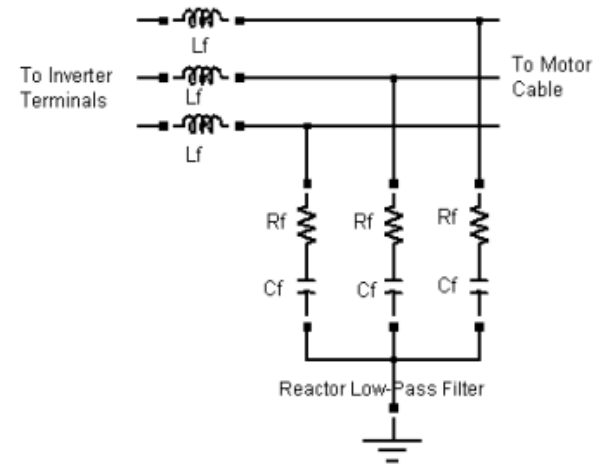

Figure 23. Second order low-pass filter

In this case, based on the [9] filter parameters are:

$\mathrm{Rf}=60 \Omega$

$\mathrm{Lf}=0.925 \mathrm{mH}$

$\mathrm{Cf}=0.0102 \mu \mathrm{F}$

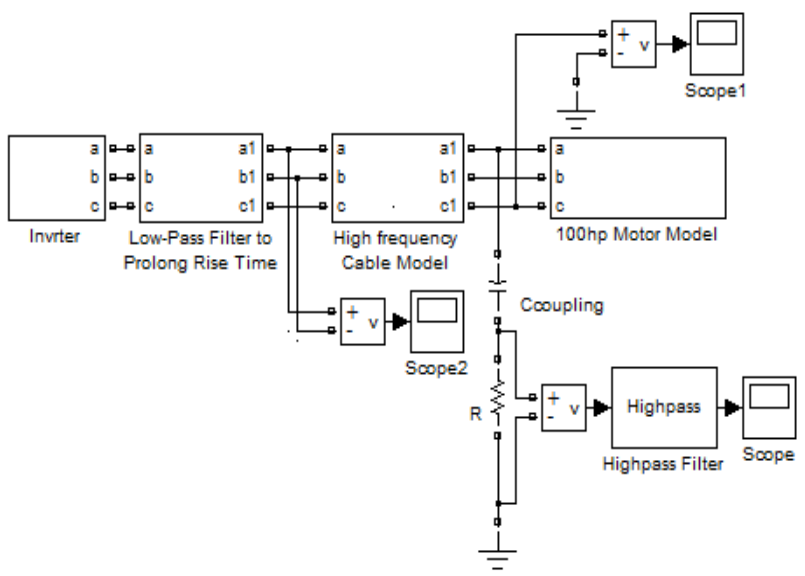

Figure 24. Block diagram of on-line partial discharge with inverter output filter

By using the filter as shown in Figure 24 over voltage at machine terminal reach to 750 volts that is 100 volt more than DC bus bar voltage. However, the coupling capacitor $500 \mathrm{pF}$ is used. This filter increases the inverter rise time, but not inside the inverter, so the reverse recovery effects will prevent.

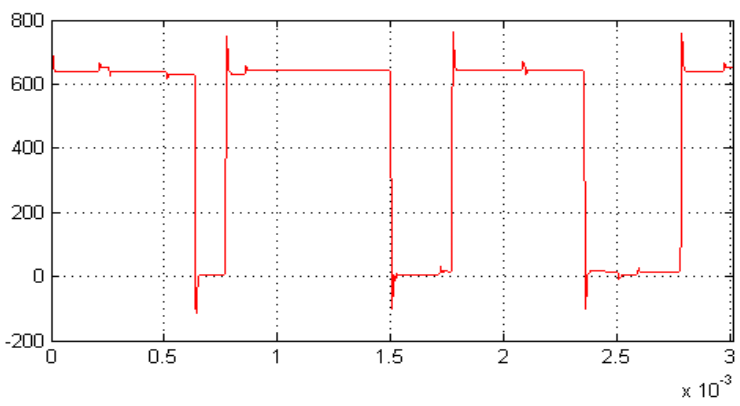

Figure 25. Over voltage at machine terminal with inverter output filter

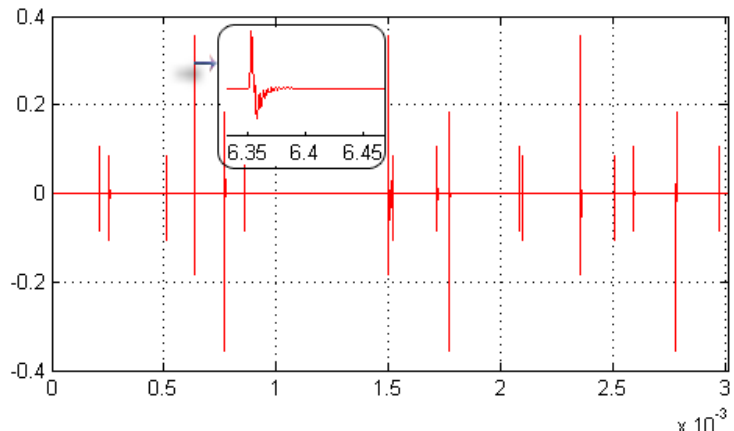

Figure 26. Detected partial discharge with inverter output filter 
As shown in figure 25 , we observe that the amplitude of partial discharge signal is much reduced. So using this method, reduces the over voltage at the terminals of the machine and the amplitude of partial discharge signal, which can be reduce detection sensitivity of partial discharge phenomena. Also by this method we can detect rising and falling edges of signals and used for inverter preventive maintenance and predict errors before they occur. The below table shows the results of the simulation.

TABLE I. RESULT OF SIMULATION

\begin{tabular}{|c|c|c|c|}
\hline $\begin{array}{c}\text { Coupling } \\
\text { capacitor } \\
\text { capacity }\end{array}$ & $\begin{array}{c}\text { Max. voltage } \\
\text { of machine } \\
\text { terminal }\end{array}$ & $\begin{array}{c}\text { Max. voltage } \\
\text { of partial } \\
\text { discharge }\end{array}$ & $\begin{array}{c}\text { attenuation time } \\
\text { of partial } \\
\text { discharge }(\mu \mathrm{s})\end{array}$ \\
\hline $80 \mathrm{pF}$ & $1196 \mathrm{v}$ & $1.4 \mathrm{v}$ & 30 \\
\hline $500 \mathrm{pF}$ & $1195 \mathrm{v}$ & $9.2 \mathrm{v}$ & 20 \\
\hline $5 \mathrm{nF}$ & $1110 \mathrm{v}$ & $32.2 \mathrm{v}$ & 13 \\
\hline $50 \mathrm{nF}$ & $882 \mathrm{v}$ & $42 \mathrm{v}$ & 5 \\
\hline $500 \mathrm{nF}$ & $833 \mathrm{v}$ & $43.3 \mathrm{v}$ & 4 \\
\hline $5 \mu \mathrm{F}$ & $828 \mathrm{v}$ & $43.5 \mathrm{v}$ & 3.8 \\
\hline $50 \mu \mathrm{F}$ & $827 \mathrm{v}$ & $43.5 \mathrm{v}$ & 3.8 \\
\hline By Filter & $750 \mathrm{v}$ & $0.35 \mathrm{v}$ & 3.8 \\
\hline
\end{tabular}

\section{CONCLUSION}

Over voltage and partial discharge could due to cable length and rise time of the inverter.

By increasing coupling capacitor capacity, we can decrease over voltage at machine terminals and attenuation time of partial discharge signal, and the amplitude of the partial discharge signal increases and it increase the signal to noise ratio and system sensitivity will be higher.

Installing inverter output filter can increase the rise time and decrease the over voltage at the terminals of the machine and the partial discharge signal amplitude, so it could reduce sensitivity of detecting of partial discharge phenomenon. As indicated in Figures, partial discharge signal amplitude reach to $0.35 \mathrm{~V}$ by mount inverter output filter (which increases the rise time to $2 \mu \mathrm{s}$ ) while without filter installed and with the $0.1 \mu$ s of rise time, partial discharge signal amplitude reach to $9 \mathrm{~V}$.

Measuring partial discharge signals in the form of this article have explicit results, so the method is enough accuracy.

The setting of filters should be flexible because the parameters of machines and inverters are different. The series resistance with coupling capacitor must be the lowest possible so impulse can be seen after passing through the system.

\section{REFERENCES}

[1] L. E. Bewley, Travelling Waves on Transmission Systems. New York Wiley, 1951, 2nd ed.

[2] D.Leggate, J.Pankau, D.W.Schlegel, R.J. Kerk-man, G.L.Skibinski, "Reflected Waves and Their Associated Current," IEEE Trans. On Industry application, vol. 35, pp. 1383-1392, Nov/Dec. 1999.

[3] E. Person, "Transient Effects in Application of PWM Inverters to Induction Motors," IEEE Trans. On Industry Application, vol. 28, pp. 1095-1101, Sep/Oct. 1992.

[4] IEEE Trial-Use Guide to the Measurement of Partial Discharges in Rotating Machinery, IEEE Standard 1434-2000, Apr. 2000.

[5] H,Zhu, V.Green, M.Sasic, S.Halliburton, "Development of High Sensitivity Capacitors for PD Measurement in Operating Motors and Generators," in Proc. 2000 IEEE properties and Applications of Dielectric Mat. Conf., pp. 571 - 574.

[6] B.Mirafzal, G.L.Skibinski, M.Tallam, "Determination of Parameters in the Universal Induction Motor Model," IEEE Trans. On Industry Applications, vol. 45, pp. 142-151, Jan/Feb. 2009.

[7] A.F.Moreira, T.A.Lipo, R.Reese, G.Venkataramanan and S.Bernet, "High Frequency Modelling for cable and Induction Motor Overvoltage Studies in Long Cable Drives," IEEE Trans. On Industry Applications, vol. 38, pp. 1297-1306., Sep/Oct. 2002.

[8] H. Zhu, V. Green, M. Sasic, and S. Halliburton "Increased sensitivity of capacitive couplers for in-service PD measurement in rotating machines", IEEE Transactions on Energy Conversion, Vol. 14, No. 4, December 1999,p1184-119.

[9] A.vonJouanne, P.N.Enjeti, "Design Considerations for a Inverter Output Filter to Mitigate the Effects of Long Motor Leads in ASD Applications," IEEE Trans. On Industry Applications, vol. 33, pp. 1138-1145, Sep/Oct. 1997.

[10] Daniel F. Ortega, Francesco Castelli-Dezza,"Online Partial Discharges Test on Rotating Machines Supplied by IFDs", 2010 IEEEXIX International Conference on Electrical Machines, Rome. 